\title{
Atividade e participação de idosos institucionalizados em oficinas terapêuticas: contribuições de um projeto de extensão
}

Activity and participation of institutionalized old people in therapeutic (offices) workshops: contributions from an

extension project

Actividad y participación de años institucionalizados en oficinas terapéuticas: contribuciones de un proyecto de extensión

\author{
Bruno Costa Poltronieri \\ Ana Caroline Marinho Costa Reis \\ Stephani Ribas Rocha \\ Amauri Coelho dos Santos \\ Lisete Ribeiro Vaz
}

RESUMO: Este trabalho consistiu em analisar a participação de idosos, institucionalizados, em oficinas terapêuticas por meio de um projeto de extensão. Para alcançar o objetivo, realizou-se a análise temática dos diários de campo dos integrantes do projeto denominado "Oficinas terapêuticas no contexto de uma Instituição de Longa Permanência para Idosos: Uma proposta de inserção pela Terapia Ocupacional". Constatou-se que as oficinas foram dispositivos potentes para criação e fortalecimento de laços sociais, propulsoras de reminiscências, experimentações e autonomia.

Palavras-chave: Envelhecimento; Terapia Ocupacional; Institucionalização. 
ABSTRACT: This work analyzed the participation of institutionalized elderly in therapeutic workshops through an extension project. To achieve this objective, it was made a thematic analysis of the field diaries of the project members entitled "Therapeutic Workshops in the Context of a Long-Term Care Institution for the Elderly: A Proposal for Insertion by Occupational Therapy". The workshops proved to be powerful devices for the creation and strengthening of social bonds, propellers of reminiscences, experimentations and autonomy.

Keywords: Aging; Occupational Therapy; Institutionalization.

RESUMEN: Este trabajo consistió en analizar la participación de ancianos, institucionalizados, en talleres terapéuticos a través de un proyecto de extensión. Para alcanzar el objetivo, se realizó el análisis temático de los diarios de campo de los integrantes del proyecto denominado "Talleres terapéuticos en el contexto de una Institución de Larga Permanencia para ancianos: una propuesta de inserción por la Terapia Ocupacional". Se constató que los talleres fueron dispositivos potentes para la creación y fortalecimiento de lazos sociales, propulsores de reminiscencias, experimentaciones y autonomía.

Palabras clave: Envejecimiento; Terapia Ocupacional; Institucionalización.

\section{Introdução}

O envelhecimento populacional é um fenômeno mundial complexo, que gera mudanças sociais e econômicas tanto nos países desenvolvidos quanto naqueles em desenvolvimento. Chegar à velhice, portanto, é uma realidade, mesmo em países que enfrentam graves problemas como desigualdade social, pobreza e fragilidade dos serviços garantidos por políticas públicas.

No Brasil, este fenômeno ocorre através de acelerado processo de transição demográfica, com crescimento acentuado da população idosa, redução dos níveis de fecundidade, mudança no papel social da mulher e reorganização dos arranjos familiares (Camarano, \& Mello, 2010).

Projeções populacionais indicam que, em 2020, o Brasil será o sexto país do mundo em número de idosos, com um contingente superior a 30 milhões de pessoas (Veras, 2009). 
Esse cenário levanta questões acerca do funcionamento dos serviços de atenção ao idoso, em especial aqueles serviços destinados aos que possuem como única alternativa a moradia em Instituições de Longa Permanência para Idosos (ILPI). O acolhimento institucional, em geral, decorre da prevalência de doenças crônicas, redução de autonomia e independência, vulnerabilidade social, perda de vínculos familiares, ou devido à situação de violência e abandono.

Em grande número, os idosos institucionalizados possuem limitados recursos financeiros e sociais, estão sem moradia e com ruptura de seus laços familiares e comunitários. A institucionalização se torna mais expressiva na população idosa em vulnerabilidade social ou situação de ruptura de direitos.

As ILPI são instituições públicas, privadas ou filantrópicas destinadas à moradia coletiva de pessoas com idade igual ou superior a 60 anos que possam ter vínculos familiares rompidos ou não, sendo responsáveis por promover cuidado integral e por garantir condições de liberdade, dignidade e cidadania. São gerenciadas pelo Sistema Único de Assistência Social (SUAS) e não se caracterizam como espaços de tratamento clínico. Nas legislações relacionadas, encontram-se orientações para desenvolvimento de estratégias de integração entre os idosos residentes e de fortalecimento de vínculos familiares e comunitários (Brasil, 2005).

No entanto, esses estabelecimentos ainda não se reconhecem como ILPI, apresentando-se sob diversas nomenclaturas. Suas ações não são sistematizadas, tornando-os espaços heterogêneos, com ações difusas e geralmente pontuais (Veras, 2009). Camarano e Kanso (2010) observaram que, frequentemente, não é comum promover estratégias de integração entre os idosos, sendo estas estratégias declaradas por menos de $50 \%$ das instituições pesquisadas.

De forma geral, estas instituições são pouco flexíveis quanto aos horários estabelecidos e às atividades rotineiras de cuidados básicos da vida diária; não costumam incentivar o envolvimento dos idosos em outras atividades de seu interesse ou engajamento em novos papéis sociais (Camarano, \& Kanso, 2010).

Os terapeutas ocupacionais, assim como os demais profissionais da saúde, estão sendo convocados a atender ao crescente número de idosos, se instrumentalizando na temática e conhecendo a realidade dos serviços. 
Para Almeida, Ferreira e Batista (2011), é imprescindível que o terapeuta ocupacional inserido nos serviços de atenção ao idoso esteja preparado para compreender as peculiaridades desse recorte populacional, contribuindo para a promoção dos direitos de cidadania, independência, autonomia, inclusão e participação social.

Dentro da ampla gama de saberes que envolvem a Terapia Ocupacional como área de conhecimento, os terapeutas ocupacionais têm lançado mão de recursos terapêuticos diversos para atender seus clientes de forma individual, em grupos e/ou oficinas, desenhando estratégias de intervenção. As oficinas terapêuticas são dispositivos utilizados pelos terapeutas ocupacionais no Brasil, sendo bastante difundidas nos serviços de saúde mental.

Atividades expressivas, criativas, corporais, estéticas e sociais são realizadas com o objetivo de possibilitar vivências diferentes no cotidiano das instituições. Para Montrezor (2013), as oficinas terapêuticas ajudam a desenvolver o "fazer junto", possibilitando o compartilhamento de experiências e facilitando a interação social, a partir dos mais variados recursos, através de comunicação verbal e/ou não verbal.

Nos hospitais psiquiátricos, os grupos e as oficinas terapêuticas representaram o rompimento com as práticas tradicionais da psiquiatria. Potencializados pelo redimensionamento político no campo da saúde mental no Brasil, as oficinas e os grupos apontavam para o mesmo sentido dos princípios de cidadania e direitos humanos do movimento de desinstitucionalização, colocando o louco, pela primeira vez, como sujeito de direitos. As oficinas procuravam produzir sentido, buscando a subjetivação e permitindo que processos criativos surgissem a partir da experiência (Galletti, 2004).

Lima (2004) destaca a importância das oficinas na clínica em saúde mental como um lugar de aprendizagem, de produção, de intercâmbio, de ampliação das relações e de mergulho em um universo cultural único, entendendo que estes processos acontecem de forma singular, porém inseridos em um coletivo.

Embora tenham ganho expressividade no campo da saúde mental, as oficinas terapêuticas não pertencem a um campo fixo. São apontadas por Galletti (2004) como pertencentes a um campo híbrido, sem identidade, constituído a partir de experimentações diversas, sem um padrão ou único modelo de intervenção e estando sempre abertas à intersecção com vários campos de saberes. Dessa forma, as oficinas terapêuticas são sensíveis a problematizações de outros campos, podendo ser utilizadas como recurso potente pelo terapeuta ocupacional junto a idosos institucionalizados e em espaços onde há efervescente discussão de definições e práticas. 
Nessa perspectiva, este trabalho teve como objetivo analisar a participação de idosos moradores de uma Unidade Municipal de Reinserção Social em oficinas terapêuticas e suas percepções em relação às atividades desenvolvidas em um projeto de extensão, vinculado ao curso de Terapia Ocupacional de uma instituição federal de ensino no Rio de Janeiro, Brasil.

\section{Oficinas terapêuticas como dispositivo de cuidado junto a idosos institucionalizados: possibilidades de intervenção}

Uma problemática que se observa muitas vezes no interior das ILPI, segundo Prado e Araújo (2014), é a intensidade e a radicalidade com que a subjetividade e a identidade dos moradores são usualmente subestimadas. A constituição de novos vínculos afetivos e laços comunitários é pouco favorecida. Além disso, há escassa promoção de atividades significativas que possam identificar, estimular e favorecer as necessidades cognitivas, funcionais, afetivas e sociais para propiciar um envelhecimento participativo e digno.

Geralmente as instituições destinadas a idosos são constituídas de forma rígida, com horários bem estabelecidos e atividades, quando ocorrem, rotineiras em espaços comunitários pouco acolhedores e restritos aos cuidados básicos da vida diária "sem possibilitar qualquer tipo de envolvimento em atividades ou engajamento em novos conhecimentos e realizações" (Prado, \& Araújo, 2014, p. 242).

O envelhecimento marcado pela involução do corpo biológico, “deve ser estimulado na busca de novas relações, com sentido e interesse pelo outro, incentivando trocas e circulação libidinal na promoção de senescência" (Prado, \& Araújo, 2014, pp. 242-243). Entendendo-se senescência como o envelhecimento normal, o estímulo citado pelos autores pode ser referenciado no outro, ou em novas relações, além de poder ser resgatado pela atividade humana.

Entende-se que é a partir das atividades humanas que as pessoas se relacionam, tornam-se produtivas na sociedade, vivenciam a cultura da qual fazem parte e se tornam quem elas são. Isso justifica a relevância da atividade humana na prática da Terapia Ocupacional, a qual se interessa pelas atividades realizadas pelos sujeitos, na vida cotidiana. Segundo Castro, Lima e Brunello (2001), é nesse processo de realização de atividades em Terapia Ocupacional que se estabelece uma nova maneira de fazer e se relacionar e isto envolve construção de uma vida cotidiana com qualidade. 
Se imerso nesse fazer que "estimula-o a continuar a fazer planos", o idoso estabelecer contatos sociais, tornando-se ativo, participante de sua comunidade, autônomo, aos olhos da sociedade, um velho sem o estigma de velho (Ximenes, \& Côrte, 2010, p. 32), tal fazer pode e deve ser resgatado e favorecido por meio de oficinas terapêuticas.

Embora historicamente as oficinas sejam práticas em instituições psiquiátricas ou de atenção psicossocial, tais intervenções estão longe de pertencer exclusivamente ao campo da saúde mental, conforme Galletti (2004, p. 36) nos aponta:

[...] assim, as oficinas localizam-se num campo híbrido, móvel, instável, sem identidade, feito de experimentações múltiplas e aberto à intersecção com vários campos de saberes, o que pode garantir a elas um espaço menos restrito - como o de especialidade em saúde mental - e mais efervescente quanto a problematizações e descontinuidades produzidas, criando, assim, uma nova cultura de intervenções, escavada por essas experiências que pouco se intimidam com o discurso técnico vigente e que tentam escapar do modelo terapêutico normatizador.

\section{Percurso metodológico}

Este manuscrito é oriundo de um projeto de pesquisa e extensão denominado "Oficinas terapêuticas no contexto de uma Instituição de Longa Permanência para Idosos: Uma proposta de inserção pela Terapia Ocupacional", vinculado a uma instituição de ensino da rede federal localizada no município do Rio de Janeiro. Antes de as ações se iniciarem, houve produtivo diálogo com a equipe da unidade sobre a proposta do projeto. Após o aceite pela direção, o projeto foi submetido e aprovado pelo comitê de ética e pesquisa da instituição de ensino sob o parecer n. ${ }^{\circ} 1.225 .792$ e, em seguida, foi autorizado pela Secretaria Municipal de Desenvolvimento Social da Prefeitura do Rio de Janeiro.

Embora inicialmente elaborado para atender idosos de uma ILPI, constatou-se que, de acordo com a legislação vigente, o dispositivo, na verdade, se caracterizava como uma Unidade Municipal de Reinserção Social (UMRS), na qual os idosos residiriam até que conseguissem ser reinseridos na comunidade ou em ILPI. Não houve nenhuma reinserção de fato, durante o período de execução da proposta extensionista. 
O projeto ocorreu em dois períodos: iniciou-se em janeiro de 2016 até julho deste mesmo ano; e a segunda etapa se iniciou em setembro de 2016 e se encerrou em março de 2017. Devido a ocorrências no calendário da Instituição de Ensino, houve menos encontros na segunda etapa. O projeto se desenvolveu ao longo de 30 encontros. As atividades denominadas "oficinas terapêuticas" ocorriam às quartas-feiras, com duas horas de duração, tendo sido realizadas por, no mínimo, três discentes de Terapia Ocupacional e um docente do curso. Após as oficinas, todos se reuniam em rodas de conversa para refletirem sobre o encontro do dia.

A equipe envolvida no projeto enfatizou que os idosos moradores da unidade não eram obrigados a participar das oficinas terapêuticas ou da pesquisa. Esclareceu também que todos os que aceitassem participar da pesquisa precisariam assinar o Termo de Consentimento Livre e Esclarecido (TCLE).

De um total de 29 moradores, 19 idosos participaram da pesquisa. Procurou-se conhecer um pouco mais o perfil sociodemográfico dos idosos que haviam assinado o TCLE, por meio do preenchimento de um questionário sempre feito com algum membro do projeto. Buscaram-se também informações sobre os moradores nos prontuários da instituição. Para resguardar o sigilo e a identidade de todos os participantes deste estudo, utilizaram-se nomes fictícios para relatar os fatos ocorridos ao longo do projeto.

Todas as oficinas eram registradas pelos discentes no mesmo dia em que ocorriam os encontros e as atividades planejadas. Eles descreviam a participação dos idosos nas oficinas e escreviam no diário de campo suas próprias percepções acerca de como as oficinas impactavam ou não, no cotidiano dos idosos institucionalizados. $\mathrm{O}$ diário de campo constituiu-se, portanto, no principal instrumento de coleta de dados.

O diário de campo é um instrumento rico para se registrarem observações, comentários e reflexões. É destinado ao uso individual do profissional, aluno ou pesquisador. Além disso, ele facilita criar o hábito de observar com atenção, de descrever com precisão e refletir sobre os acontecimentos de um dia de trabalho. Para isso deve ser usado diariamente: para garantir o maior detalhamento possível de todas as situações ocorridas em dado momento (Lima, Mioto, \& Dal Prá, 2007). Assim, o diário de campo, além de conter as descrições e percepções dos fenômenos, é um instrumento que permite ao pesquisador analisar e compreender as interações ocorridas entre os sujeitos observados e os pesquisadores observadores (Weber, 2009), todos participantes (ainda que em funções distintas) das atividades proporcionadas no local, para a produção do conhecimento. 
Para compreender o conteúdo manifesto nos diários de campo e o que as oficinas terapêuticas possibilitaram aos idosos, optou-se por analisar o material através de análise temática, método oriundo da análise do conteúdo.

Assim, este estudo trata de uma pesquisa de abordagem qualitativa, na qual analisaram-se os diários de campo dos discentes que planejaram e coordenaram as atividades propostas.

Deve-se considerar que, ao longo de um ano de projeto, seis discentes participaram ativamente desde a concepção das atividades até o encerramento das oficinas.

Após leitura atenta e exaustiva dos diários de campo, categorizaram-se os resultados em duas temáticas resultantes da análise. Tais temáticas dialogam e se relacionam entre si. São elas: 1) Oficinas como facilitadoras para fortalecimento e criação de laços sociais; 2) Oficinas como propulsoras da autonomia dos sujeitos.

\section{Resultados e discussão}

Ressalta-se que os resultados descritos neste estudo, referem-se especificamente ao trabalho realizado junto aos 19 idosos moradores do equipamento socioassistencial que aceitaram participar da presente pesquisa. Entre estes participantes, dez eram do sexo masculino e nove do sexo feminino, com faixa etária entre 62 e 89 anos uma média de idade de 74,5 anos. Estes dados de gênero e idade são semelhantes aos achados de Borges, et al. (2015).

Em relação ao estado civil, doze relataram ser solteiros, onze referiram não ter filhos e quatorze são alfabetizados. O tempo de moradia dos idosos na instituição, no período em que o estudo foi realizado, variava de seis meses a seis anos. Constatou-se que alguns idosos já vinham de outras instituições. Contudo, pouco se conseguiu saber desse histórico institucional de cada pessoa.

Os dados referentes ao perfil dos idosos participantes do estudo estão descritos na tabela 1. 
Tabela 1- Características sociodemográficas dos idosos que participaram das atividades

\begin{tabular}{|c|c|}
\hline Variáveis & (n) \\
\hline Amostra & $\mathrm{N}=19$ \\
\hline \multicolumn{2}{|l|}{ Sexo } \\
\hline Feminino & 09 \\
\hline Masculino & 10 \\
\hline Faixa etária & $62-89$ \\
\hline \multicolumn{2}{|l|}{ Institucionalização } \\
\hline 06 meses -01 ano & 07 \\
\hline $03-04$ anos & 06 \\
\hline $05-06$ anos & 06 \\
\hline \multicolumn{2}{|l|}{ Escolaridade } \\
\hline Não alfabetizado & 03 \\
\hline Fundamental incompleto & 09 \\
\hline Fundamental completo & 03 \\
\hline Médio completo & 01 \\
\hline Superior completo & 01 \\
\hline Não informaram & 02 \\
\hline \multicolumn{2}{|l|}{ Vida conjugal } \\
\hline Casados & 03 \\
\hline Solteiros & 12 \\
\hline Divorciados & 01 \\
\hline \multicolumn{2}{|l|}{ Filhos } \\
\hline Sim & 08 \\
\hline Não & 11 \\
\hline \multicolumn{2}{|l|}{ Religião } \\
\hline Católicos & 09 \\
\hline Evangélicos & 03 \\
\hline Espíritas & 02 \\
\hline Sem religião & 01 \\
\hline Não informaram & 04 \\
\hline \multicolumn{2}{|l|}{ Doenças crônicas } \\
\hline Sim & 12 \\
\hline Não informaram & 07 \\
\hline \multicolumn{2}{|l|}{ Uso de Medicação } \\
\hline Sim & 18 \\
\hline Não & 01 \\
\hline \multicolumn{2}{|l|}{ Quedas } \\
\hline Sim & 03 \\
\hline Não & 16 \\
\hline \multicolumn{2}{|l|}{ Atividade física } \\
\hline Sim & 01 \\
\hline Não & 18 \\
\hline
\end{tabular}

(n)= número de idosos 


\section{Oficinas como facilitadoras de fortalecimento e criação de laços sociais}

Em sua maioria, os moradores da unidade possuíam uma história marcada por violências, privações de direitos, ruptura de laços familiares e/ou sociais, e adoecimento crônico. Alguns já estiveram em situação de rua, outros já haviam morado em instituições psiquiátricas, e também havia o caso de quem pouco sabia de/pouco se lembrava/queria contar sua história de vida. Muitos possuíam limitações físicas e sensoriais que dificultavam sua participação em atividades comunitárias externas à Unidade. Isso se devia à restrição de mobilidade ou a algum déficit físico ou a déficit cognitivo ainda a esclarecer. Os idosos mais independentes eram os que menos participavam das atividades propostas nas oficinas.

Observou-se que, apesar de muitos estarem há anos na instituição, aconteciam poucos momentos de trocas entre os idosos, fosse de convivência, de interação ou de experimentação, sendo bastante frequente o registro, nos diários de campo, de que os idosos "participam das atividades, porém com pouca interação entre os mesmos".

Esse comportamento de pouca convivência, e até mesmo hostil, entre muitos idosos institucionalizados pode ser explicado por uma série de questões referentes às dificuldades do idoso de se adaptar à rotina e normas da instituição, à falta de privacidade, ao distanciamento em relação à sociedade e aos entes queridos (quando existiam) e ao compartilharem de um espaço com outras pessoas desconhecidas (Silva, et al., 2006). Neste cenário, muitos idosos se isolam e procuram pela atenção individual da equipe profissional da instituição.

Essa grande procura pelos membros do estudo foi observada nas oficinas, pois os idosos procuravam bastante os integrantes do projeto para conversar, tirar dúvidas sobre as atividades ou mostrar seus pertences. Tal isolamento e afastamento social desencadeiam um frágil suporte social entre os moradores.

Um estudo de caso de Rodrigues e Silva (2013), que teve como objetivo identificar a composição da rede de apoio social de idosos institucionalizados, constatou que poucos idosos institucionalizados recebiam algum apoio (material, afetivo, emocional etc.) de familiares e amigos externos à ILPI onde residiam, o que indica que o apoio mútuo entre os idosos moradores da instituição seria uma estratégia importante para compor uma rede a qual os próprios idosos poderiam se ajudar e amparar um ao outro. 
Ainda segundo Rodrigues e Silva (2013), idosos institucionalizados têm pouca motivação para cultivar amizades com outros moradores, e possuem atitudes preconceituosas e pouco colaborativas em relação aos demais moradores. Essa afirmação pode ser constatada em uma das falas registradas em diário de campo em que Oswaldo, um idoso independente, afirma em conversa para um dos discentes:

"Me entenda bem, eu estou em um nível e eles em outro. Eles são chatos!" (Registro em diário de campo)

Tendo em vista essa dificuldade para criar ou fortalecer laços comunitários, a equipe do projeto buscou favorecer a interação positiva e o fortalecimento de vínculos entre os próprios idosos, ainda que outras possibilidades de experimentação e novos desdobramentos pudessem emergir com a realização das atividades. Isso indica que havia a compreensão de que, em um grupo permeado pela criação e pelo fazer humano, coordenado por terapeutas ocupacionais, a tarefa iria para além da " realização das atividades em si ou na concretização de um produto final palpável” [... alcançando também...] "a aprendizagem e o crescimento pessoal que esse 'fazer junto', esse 'fazer com' possibilitam aos integrantes." (Nicolau, 2015, p. 265).

Ao se detectar a dificuldade dos idosos de se identificarem enquanto um coletivo, as oficinas terapêuticas que inicialmente foram planejadas para um grupo, porém com atividades individualizadas, foi repensada para que algumas tarefas fossem realizadas em duplas ou trios, o que foi um desafio para os integrantes do projeto, pois obrigava os coordenadores das oficinas a ter mais atenção e sensibilidade para mediar as tensões que ali pudessem eclodir, pois, como Lima (2015, p. 186) afirma: "uma experiência grupal pressupõe o intercruzamento do singular e do coletivo; essas duas dimensões nem sempre estão em harmonia e consonância". Assim, buscou-se um equilíbrio ao fracionar ainda mais as atividades das oficinas em pequenos grupos, para que as tensões não fossem uma constante, e para que momentos de criação e experimentação individuais fossem favorecidos, sempre que necessário.

As oficinas possibilitaram encontros que até então não tinham sido permitidos, ainda que todos morassem no mesmo ambiente. Isso fica evidente no caso de um idoso chamado José, que descobriu, em oficina, em uma atividade de confecção de crachás, que o senhor sentado a seu lado também se chamava José. Esta situação está assim descrita no diário de campo: 
“...Descobriu que o José Paulo é seu xará e ficou muito surpreso (de fato observa-se falta de relação interpessoal); demonstrou felicidade $e$ o cumprimentou (estavam sentados um ao lado do outro) e começaram a conversar..." (Registro em diário de campo)

Ao longo das oficinas terapêuticas, procurou-se reforçar o senso de identidade, de tal modo que os participantes em momentos oportunos falassem seus nomes e fizessem um pequeno relato sobre o que significou aquele encontro. Tal condução facilitou que eles pudessem se referir uns aos outros pelos nomes.

À medida que o tempo transcorreu, e as oficinas foram se consolidando, foi possível notar pequenos gestos de solidariedade e apoio mútuo entre alguns moradores que, até então, pouco interagiam ou participavam das atividades em oficinas. É o caso de um homem que, ao perceber o problema de visão de uma senhora a seu lado, recortou retalhos de tecido para que ela conseguisse fazer sua mandala. Outro exemplo desta mesma natureza é descrito a seguir, conforme registro em diário de campo:

\section{"Nilson e Lavínia também se ajudaram... foi muito gratificante ver esses dois residentes nesse momento de troca, pois os mesmos costumavam ficar isolados dos demais e durante toda a atividade os dois riam e conversavam. Lavínia dizia que ele era muito engraçado." (Registro em diário de campo)}

Houve também momentos de interação mais coletiva, ainda que fosse de maneira pontual, como em um dia em que a oficina foi finalizada com um bingo:

"Todos jogaram e interagiram entre si; essa foi a primeira vez que houve interação entre todos os participantes; foi muito gratificante ver esse acontecimento." (Registro em diário de campo).

A grupalidade conferida pelas oficinas era potente para promover a convivência entre todos naquele espaço. Conviver significa experimentar um espaço compartilhado, produzir laços, produzir encontros (como o de José e José Paulo, citado anteriormente), dar relevo à produção de subjetividade, evidenciar relações de poder, conflitos, tensões e saberes distintos, conforme afirmam Ferigato, Silva e Lourenço (2016, p. 855): "A afirmação da produção de convivência na diferença é também dizer 'sim' à inserção social, à possibilidade de se relacionar com o outro, em resistência à opinião, à neutralidade e à cristalização dessas mesmas relações". 
As oficinas terapêuticas, que inicialmente traziam certo desconforto e desconfiança para alguns idosos, gradativamente foram sendo ressignificadas por alguns participantes, na medida em que passaram a comparecer espontaneamente aos encontros e se permitiram experimentar as diversas atividades propostas em contato com o outro.

Segundo Nicolau (2015, p. 269), as atividades concretizadas coletivamente "possibilitam o aprender a fazer coisas com ou sem apoio do outro, mas também podem fazer com o outro e com isso os atores podem reconhecer a potência e os desafios desse aprendizado", pois além das habilidades motoras e cognitivas que são favorecidas, os participantes puderam lidar com os afetos que permeiam o convívio social.

Assim, para que haja afeto, as oficinas devem estar longe de ser uma prática imposta. Pádua e Morais (2010) acrescentam que também a escuta se constitui como um importante elemento para que um sujeito possa compartilhar suas experiências e sentimentos e para perceber suas idiossincrasias nas oficinas, isto é, nos fazeres.

Tal escuta era imprescindível no momento em que, ao estar fazendo uma atividade em oficina, o idoso evocava alguma reminiscência associada subjetivamente à atividade que estava sendo realizada. Este foi o caso da senhora Ivone que fez um desenho bastante detalhado com uma casa com vasta área verde, e uma árvore que parecia uma palmeira. Ao falar de sua produção, ela disse que aquilo "fazia lembrar algum lugar" e, em seguida, finalizou que era lembrança que ela tinha de uma "casa em que morou em Minas Gerais".

Dessa forma, as oficinas terapêuticas não visam apenas ao "ocupar" desprovido de sentido e nem mesmo ao entretenimento. Elas visam, sobretudo, a "promover a reinserção social por meio de ações que envolvam o trabalho e a autonomia do sujeito" (Monteiro, \& Loyola, 2009, p. 438).

Tendo em vista que a condição de institucionalização, muitas vezes, leva o idoso a ser subjetivamente suprimido pela rotina rígida de convivências e horários, as oficinas terapêuticas podem proporcionar novas formas de ocupação e experimentação que possibilitam aos idosos institucionalizados almejarem novas possibilidades de viver.

Os integrantes, por meio das atividades contidas nas oficinas, podem descobrir novos interesses, habilidades e potencialidades, e estas podem originar novos desdobramentos em relação ao fazer humano (Castro, Lima, \& Brunello, 2001; Costa, et al., 2013). 
Tal ideia é expressa em um estudo de Silva, et al. (2017) que observaram que, mesmo com limitações, alguns idosos buscam uma forma de ocupação que lhes traga prazer e satisfação, como um mecanismo de adaptação em um contexto de vulnerabilidade e fragilidade, decorrente da institucionalização. Estes autores sinalizam que "uma das formas de se viver plenamente essa fase da vida seria experimentar atividades que proporcionem satisfação pessoal e contribuam para manutenção da identidade, da personalidade do indivíduo e a maneira de ver e pensar o mundo" (Silva, et al., 2017, p. 8).

Contudo, vale fazer a ressalva de Galleti (2004), em relação à naturalização, que a prática de oficina pode ocasionar de aprisionar e apassivar o dispositivo nas intervenções institucionais. Essa observação sempre foi uma preocupação dos integrantes do projeto junto aos idosos, pois, no início das atividades, parte significativa dos idosos comparecia às oficinas porque "mandavam" ir. Contudo, sempre procurou-se deixar claro que participar, ou não, era uma escolha de cada um, e que eles eram livres para permanecer, ainda que só para observar, ou sair no momento desejado.

Na realização das atividades em oficinas, sobretudo no início, os idosos questionavam o que era "certo" ou "errado" nas atividades. Apostava-se que eles tivessem autonomia de escolher sobre cada ação, cada ocupação e cada experimentação.

\section{Oficinas como propulsoras da autonomia dos sujeitos}

A autonomia refere-se à capacidade que o ser humano tem de tomar decisões sobre si mesmo e de assumir o controle de sua vida (Oliveira, \& Alves, 2010). Nas oficinas realizadas nesta Unidade, a autonomia estava presente e era exercida com a decisão demonstrada pelos idosos de participar, ou não, das oficinas propostas. Era evidente que alguns idosos inicialmente participavam das atividades de maneira incomodada, como o caso de Helenita, que disse:

"... que não estava entendendo e perguntou se podia sair do grupo." (Registro em diário de campo).

Outros participantes tinham clareza da proposta e escolhiam estar ali desde o início, como expressa o fragmento a seguir: 
"Um idoso (José Paulo) disse que participa das oficinas porque gosta e faz bem pra ele." (Registro em diário de campo).

Oliveira e Barbas (2013) trazem reflexões acerca da autonomia. Segundo eles, o indivíduo com autonomia possui uma liberdade de pensamento para escolher as propostas que lhe são apresentadas, escolhendo sobre o que julga ser bom para ele, que favorece o seu bemestar, sua satisfação. Com os idosos institucionalizados, isso nem sempre é possível. Muitos moradores apresentavam dificuldades para escolher as propostas que lhes eram apresentadas, no momento da oficina. Abaixo, são descritas algumas impressões retiradas do diário de campo sobre essa questão:

"Estamos quase há seis meses na unidade, sempre explicando que são eles que escolhem participar das oficinas, ou não, mas mesmo assim, parece que eles não se sentem capazes de dizer que não querem participar, colocando a decisão do que eles vão fazer nas mãos da gente; talvez isso diga sobre como as escolhas deles são tratadas dentro da unidade." (Registro em diário de campo).

"Alguns não conseguem ter autonomia suficiente para escolher entre um leque de opções para atividade... escolher entre lápis, giz etc., para personalizar seu próprio crachá." (Registro em diário de campo).

A autonomia também aparece relacionada com a identidade dos idosos. Nas oficinas, um idoso conseguiu demonstrar sentimento de sentir-se bem, útil, capaz e vivo. Como identificaram Fonseca, et al. (2010), em seu estudo que teve como objetivo compreender os significados atribuídos à auto-avaliação da saúde do idoso; eles afirmam que, quando um idoso se sente capaz, fazendo sua parte, independentemente dos desafios presentes no envelhecimento, ele está mantendo sua identidade intersubjetiva.

Nos encontros e oficinas terapêuticas realizados na instituição, foi presenciado também um momento em que dois idosos puderam expressar seus desejos, solicitando a realização de uma festa junina na instituição. Algumas políticas, como a Resolução da ANVISA/DC n. ${ }^{\circ} 283$, preconizam que as instituições de longa permanência devem estimular a autonomia dos idosos e promover condições de lazer para os idosos por meio de atividades recreativas, culturais e de lazer.

Outro fato importante observado nos depoimentos dos idosos, que pode ser associado com as alterações em sua tomada de decisão, é o estabelecimento de regras e normas da instituição. 
Em geral, o excesso destas atividades pode destituir o idoso de sua própria rotina, característica semelhante às encontradas nas instituições totais (Oliveira, \& Rozendo, 2014). Note-se que esta UMRS não é reconhecida enquanto instituição total.

Essas semelhanças contribuem para problemas na hora de tomar decisão, pois, quando se deparam na posição de sujeitos com escolhas, aqueles idosos apresentam problemas devido a essas barreiras institucionais, não conseguindo, por exemplo, ao menos escolherem o que querem desenhar, como demonstra o registro: "Desenhar o quê? Desenho um gato, uma flor ou uma planta?" (Registro em diário de campo).

Os objetivos das ações dos profissionais que atuam junto a idosos, sobretudo o terapeuta ocupacional, devem estar relacionados com o envelhecimento ativo, que acontece quando é mantida a capacidade funcional e a autonomia do sujeito. Dessa forma, não há possibilidade de pensar em envelhecimento sem pensar em preservar a autonomia e a independência da pessoa idosa (Brasil, 2006).

\section{Considerações Finais}

As oficinas terapêuticas podem enriquecer a vida dos idosos institucionalizados para superação das limitações, muitas vezes, experimentadas na velhice, favorecendo o bem-estar, a participação social e a motivação para engajamento em diferentes atividades, oficinas ou até mesmo em novas ocupações.

Observou-se que a interação social e o "fazer" de atividades pouco exploradas estimularam a participação dos idosos em oficinas terapêuticas. Isso gerou vivências que contribuíram para a percepção e o reconhecimento de suas próprias capacidades durante as atividades realizadas.

O reconhecimento das capacidades pela pessoa de cada idoso favoreceu a autonomia, a capacidade decisória e a motivação para estar em atividade. Foram estes fatores que possibilitaram a expressão de sentimentos, comunicação, imaginação e a convivência entre os próprios idosos moradores e também destes com a equipe da unidade e integrantes do projeto.

O presente trabalho teve o propósito de qualificar, entre os profissionais do envelhecimento, sobretudo aos terapeutas ocupacionais, a atenção acerca das potencialidades das oficinas terapêuticas junto a idosos, no contexto de uma instituição de cuidados de longa 
duração, com pequena rede de suporte, frágeis vínculos interpessoais e em situação de fragilidade e/ou ruptura de direitos.

Chama-se a atenção para que estas oficinas atendam às necessidades de cada grupo especifico de moradores em diferentes contextos, já que outros grupos podem apresentar diferentes necessidades.

Somado a isso, propõe-se, no presente manuscrito, pensar nas oficinas terapêuticas como um recurso capaz de promover a integração entre os moradores, fortalecendo vínculos interpessoais e comunitários, garantindo as condições de liberdade, dignidade e cidadania, premissas estas que estão presentes nas políticas públicas que tratam do acolhimento institucional, e por estas são orientadas.

Como limite, este estudo não captou os discursos dos idosos na íntegra. Isso poderia dar mais subsídios para compreender o impacto e as percepções acerca das oficinas terapêuticas, sob a perspectiva dos moradores da unidade.

\section{Referências}

Rodrigues, N. C. (2001). Política Nacional do Idoso - retrospectiva histórica. Porto Alegre,RS: Estud. Interdiscip. Envelhec., 3(s/n. $\left.{ }^{\circ}\right)$, 149-158. Recuperado em 01 fevereiro, 2018, de: https://seer.ufrgs.br/index.php/RevEnvelhecer/article/viewFile/4676/2593.

Almeida, M. H. M., Ferreira, A. B., \& Batista, M. P. P. (2011). Formação do terapeuta ocupacional em gerontologia: contribuições de docentes de cursos de graduação em terapia ocupacional no Brasil. São Paulo, SP: Rev. Ter. Ocup. Univ. São Paulo, 22(3), 289-297. Recuperado em 01 fevereiro, 2018, de: file:///C:/Users/Dados/Downloads/46457Texto\%20do\%20artigo-55812-1-10-20121030\%20(1).pdf.

Borges, C. L., Silca, M. J., Clares, J. W. B., Nogueira, J. M., \& Freitas, M. C (2015). Características sociodemográficas e clínicas de idosos institucionalizados: Contribuições para o cuidado em enfermagem. Rio de Janeiro, RJ: Rev. Enferm. UERJ, 23(3), 381-387. Recuperado em 01 fevereiro, 2018, de: http://www.facenf.uerj.br/v23n3/v23n3a15.pdf.

Brasil, Ministério da Saúde. (2005). Agência Nacional de Vigilância Sanitária. Resolução da Diretoria Colegiada $n .^{\circ}$ 28, de 26 de setembro de 2005.

Brasil. (2006). Lei 8080/90; Portaria 2528/GM, de 19 de outubro de 2006. Aprova a Política Nacional de Saúde da Pessoa Idosa. Brasília (DF): Ministério da Saúde.

Camarano, A. A., \& Kanso, S. (2010). As instituições de longa permanência para idosos no Brasil. Rio de Janeiro, RJ: Rev. Bras. Est. Pop., 27(1), 234-235. Recuperado em 01 fevereiro, 2018, de: http://www.scielo.br/pdf/rbepop/v27n1/14.pdf.

Camarano, A. A., \& Mello, L. J. (2010). Introdução. In: Camarano, A. A. (Org.). Cuidados de longa duração para população idosa: um novo risco social a ser assumido?, 13-20. Rio de Janeiro, RJ: Ipea. 
Castro, E. D., Lima, E. M. F. A., \& Brunello, A. I. B. (2001). Atividades humanas e Terapia Ocupacional. In: De Carlo, M. M. R. P., \& Bartalotti, C. C. (Orgs.). Terapia Ocupacional no Brasil: fundamentos e perspectivas, 41-59. São Paulo, SP: Plexus.

Costa, C. M. L., Silva, A. P. L. L., Flores, A. B., Lima, A. A., \& Poltronieri, B. C. (2013). O valor terapêutico da ação humana e suas concepções em Terapia Ocupacional. São Paulo, SP: Cad. Bras. Ter. Ocup. UFScar, 21(1), 195-203. Recuperado em 01 fevereiro, 2018, de: file://C:/Users/Dados/Downloads/745-1359-1-PB.pdf.

Ferigato, S. H., Silva, C. R., \& Lourenço, G. F. (2016). A convivência e o com-viver como dispositivos para a Terapia Ocupacional. São Paulo, SP: Cad. Bras. Ter. Ocup. UFSCar, 24(4), 837-848. Recuperado em 01 fevereiro, 2018, de: http://www.cadernosdeterapiaocupacional.ufscar.br/index.php/cadernos/article/view/1402/790.

Fonseca, M. G. U. P., Firmo, J. O. A., Filho, A. I. L., \& Uchôa, E. (2010). Papel da autonomia na autoavaliação da saúde do idoso. São Paulo, SP: Rev Saúde Públic.,44(1), 159-165. Recuperado em 01 fevereiro, 2018, de: http://www.redalyc.org/pdf/672/67240183017.pdf.

Galletti, M. C. (2004). Oficina em saúde mental: instrumento terapêutico ou intercessor clínico? Goiânia, GO: Ed. UCG.

Lima, A. E. (2004). Oficinas, laboratórios, ateliês, grupos de atividades: dispositivos para uma clínica atravessada pela criação. In: Costa, M. C., \& Figueiredo, C. A. Oficinas terapêuticas em saúde mental - sujeito, produção e cidadania, 1-10. Coleções IPUB. Rio de Janeiro, RJ: Contra-Capa Livraria.

Lima, F. C. S., Mioto, R. C. T., \& Dal Prá, K. R. (2007). A documentação no cotidiano da intervenção dos assistentes sociais: algumas considerações acerca do diário de campo. Porto Alegre, RS: Revista Textos e Contextos, 6(1), 93-104. Recuperado em 01 fevereiro, 2018, de: http://revistaseletronicas.pucrs.br/ojs/index.php/fass/article/viewFile/1048/3234.

Lima, E. M. F. A. (2015). Um grupo de Terapia Ocupacional: tecendo vínculos, criando mundos. In: Maximino, V., \& Liberman, F. (Orgs.). Grupos e Terapia Ocupacional Formação, pesquisa e ações, 166-185. São Paulo, SP: Summus editora.

Monteiro, R. L., \& Loyola, C. M. D. (2009). Qualidade de oficinas terapêuticas segundo pacientes. Florianópolis, SC: Texto Contexto Enferm, 18(3), 436-442. Recuperado em 01 fevereiro, 2018, de:

Montrezor, J. B. A. (2013). Terapia Ocupacional na prática de grupos e oficinas terapêuticas com pacientes de saúde mental. São Paulo, SP: Cader. Bras. Ter. Ocup. UFSCar, 21(3), 529536. Recuperado em 01 fevereiro, 2018, de: http://doi.editoracubo.com.br/10.4322/cto.2013.055.

Nicolau, E. M. (2015). Grupos na atenção básica: Enraizar-se em uma comunidade. In: Maximino, V., \& Liberman, F. Grupos e Terapia Ocupacional - Formação, pesquisa e ações, 264-274. São Paulo, SP: Ed. Summus.

Oliveira, I. R., \& Alves, V. P. (2010). A pessoa idosa no contexto da bioética: sua autonomia e capacidade de decidir sobre si mesma. São Paulo, SP: Revista Kairós-Gerontologia, 13(2), 91-98. Recuperado em 01 fevereiro, 2018, de: https://revistas.pucsp.br/kairos/article/download/5368/3848.

Oliveira, J. M., \& Rozendo, C. A. (2014). Instituição de longa permanência para idosos: um lugar de cuidado para quem não tem opção? Brasília, DF: Rev Bras Enferm, 67(5), 773-779. Recuperado em 01 fevereiro, 2018, de: http://www.scielo.br/pdf/reben/v67n5/0034-7167reben-67-05-0773.pdf.

Poltronieri, B. C., Reis, A. C. M. C., Rocha, S. R., Santos, A. C. dos, \& Vaz, L. R. (2018). Atividade e participação de idosos institucionalizados em oficinas terapêuticas: contribuições de um projeto de extensão. Revista Kairós-Gerontologia, 21(4), 89-108. ISSNe 2176-901X. São Paulo (SP), Brasil: FACHS/NEPE/PEPGG/PUC-SP 
Oliveira, M. Z. P. B., \& Barbas, S. (2013). Autonomia do idoso e distanásia. Brasília, DF: Rev. Bioét, 21(2), 328-337. Recuperado em 01 fevereiro, 2018, de: http://www.scielo.br/pdf/bioet/v21n2/a16v21n2.pdf.

Pádua, F. H. P., \& Morais, M. L. S. (2010). Oficinas expressivas: uma inclusão de singularidades. São Paulo, SP: Psicol USP, 21(2), 457-478. Recuperado em 01 fevereiro, 2018, de: http://www.scielo.br/scielo.php?script=sci_arttext\&pid=S0103$65642010000200012 \& \operatorname{lng}=$ pt\&tlng=pt.

Rodrigues, A. G., \& Silva, A. A. (2013). A rede social e os tipos de apoio recebidos por idosos institucionalizados. Rio de Janeiro, RJ: Rev. Bras. Geriat. Gerontol, 16(1), 159-170. Recuperado em 01 fevereiro, 2018, de: http://dx.doi.org/10.1590/S1809-98232013000100016.

Silva, C. A., Menezes, M. R., Santos, A. C. P. O., Carvalho, L. S., \& Barreiros, E. X. (2006). Relacionamento de amizade na instituição asilar. Porto Alegre, RS: Rev.Gaúcha Enferm, 27(2), 274-283. Recuperado em 01 fevereiro, 2018, de: https://seer.ufrgs.br/RevistaGauchade Enfermagem/article/download/4606/2526.

Silva, M. R., Santos, N. P. V., Santos, R. A., Cunha, G. R., \& Torres, L. M. (2016). A percepção do idoso institucionalizado sobre os benefícios das oficinas terapêuticas. Fortaleza, CE: Rev. Bras. Promoç. Saúde, 29(suplem), 76-84. Recuperado em 01 fevereiro, 2018, de: https://periodicos.unifor.br/RBPS/article/view/6408/5215.

Veras, R. (2009). Envelhecimento populacional contemporâneo: demandas, desafios e inovações. São Paulo, SP: Rev. Saúde Pública, 43(3), 548-554. Recuperado em 01 fevereiro, 2018, de: http://www.scielo.br/pdf/rsp/v43n3/224.pdf.

Weber, F. (2009). A entrevista, a pesquisa e o íntimo, ou: por que censurar seu diário de campo? Porto Alegre, RS: Horizontes antropológicos, 15(32), 157-170. Recuperado em 01 fevereiro, 2018, de: http://www.scielo.br/pdf/ha/v15n32/v15n32a07.pdf.

Recebido em 07/10/2018

Aceito em 30/12/2018

Bruno Costa Poltronieri - Docente do curso de Terapia Ocupacional e Curso Técnico de Agente Comunitário de Saúde, Instituto Federal de Educação, Ciência e Tecnologia do Rio de Janeiro, IFRJ, campus Realengo. Mestre em Saúde Pública ENSP/Fiocruz.

URL: https://orcid.org/0000-0002-2127-0574

E-mail: bruno.poltronieri@ifrj.edu.br 
Ana Caroline Marinho Costa Reis - Discente do Instituto Federal de Educação, Ciência e Tecnologia do Rio de Janeiro, IFRJ.

E-mail: caroline.marinhosz@gmail.com

Stephani Ribas Rocha - Discente do Instituto Federal de Educação, Ciência e Tecnologia do Rio de Janeiro, IFRJ.

E-mail: stephani.rocha2@gmail.com

Amauri Coelho dos Santos - Terapeuta Ocupacional.

E-mail: coelhomendanhas@gmail.com

Lisete Ribeiro Vaz - Docente do Departamento de Terapia Ocupacional da Universidade Federal do Rio de Janeiro, UFRJ.

E-mail: lisete.vaz1@yahoo.com.br 